Jamshaid Iqbal a

Ali Sher ${ }^{\mathrm{b}}$

Parsotam Ravjee Hira ${ }^{\text {a }}$

a Department of Microbiology,

Faculty of Medicine,

Kuwait University and

b Malaria Laboratory, Ministry of

Health, Kuwait

\section{Malaria in Non-Endemic Kuwait: Detection of Very Low Level Plasmodium falciparum Infections Using Polymerase Chain Reaction}

\section{Key Words}

Plasmodium falciparum

Polymerase chain reaction

Microscopy

\begin{abstract}
Objective: Imported malaria continues to be a problem in Kuwait since most patients present with very low levels of parasitaemia. The diagnosis is often delayed or missed because of the low sensitivity of the standard stained blood smear test used for the identification of malarial parasites. In this study, we standardized a highly sensitive polymerase chain reaction (PCR) to detect malarial parasites. Methods: A total of 100 individuals presenting with various forms of infection were screened with the standard Giemsa-stained smears and were compared with the PCR for diagnosis and the sensitivity of the two methods. Results: Our results show that PCR is a highly sensitive and specific technique to detect low levels of Plasmodium falciparum parasites in clinical samples, and at least 6 cases $(12 \%)$ who were microscopically negative had PCR-detectable parasitaemia. Conclusion: The PCR is a highly sensitive assay which can detect very low levels of malarial parasites and thus is of great value to obtain accurate detection of chronic, residual and sub-patent infections in Kuwait.
\end{abstract}

\section{Introduction}

Malaria continues to be a great health problem in some of the most populated areas of the world. The global resurgence of malaria has impacted also on Kuwait, a non-endemic country. Imported malaria continues to be a problem since most of the $60 \%$ of the resident population, from 146 countries, come from endemic areas of Asia and Africa. In malaria-

\begin{tabular}{ll}
\hline KARGER & ( 1998 S. Karger AG, Basel \\
Fax +41 61 306 12 34 & 1011-7571/98/0074-0277\$15.00/0 \\
$\begin{array}{l}\text { E-Mail karger@karger.ch } \\
\text { www.karger.com }\end{array}$ & $\begin{array}{l}\text { Accessible online at: } \\
\text { http://BioMedNet.com/karger }\end{array}$
\end{tabular}

Dr. Jamshaid Iqbal, MD, MCPS, PhD

Department of Microbiology, Faculty of Medicine

Kuwait University, PO Box 24923

Safat 13110 (Kuwait)

Fax+965 5318454, E-Mail iqbal@hsc.kuniv.edu.kw 
free but vulnerable countries such as Kuwait, priority is given to early laboratory diagnosis and prompt medical treatment. Since the Gulf conflict, the annual cases of malaria ranged from 654 to 1,379 between 1992 and 1996. Plasmodium vivax was the dominant species $(>80 \%)$ but Plasmodium falciparum, Plasmodium ovale and Plasmodium malariae was also identified.

Alternative techniques for microscopic diagnosis such as direct observation of acridine orange-stained parasites in capillary centrifuged blood [1], or the sensitive molecular techniques such as DNA hybridization and polymerase chain reaction (PCR), have been developed [2-5]. However, malaria diagnosis still relies on observation of parasites in stained blood smears [6]. The Giemsa-stained thick blood smear is still the standard reference test, even if its sensitivity decreases in parallel with the density of plasmodial infection. When the parasitaemia is low, diagnosis by Giemsa-stained smears requires long periods of observation and experienced microscopists.

In Kuwait where malaria is imported and most patients present with very low levels of parasitaemia, the diagnosis is often delayed. Most cases are recognized only when parasitaemia reaches high levels. In this study, we compared the standard Giemsa-stained smears, both thick and thin, with PCR for diagnosis, and the sensitivity of the methods at low levels of parasitaemia.

\section{Materials and Methods}

Blood Samples

A total of 125 blood specimens were obtained from the following individuals:

(i) Malaria Patients. A total of 50 samples ( $\mathrm{C} 1-$ C50) were collected from malaria patients. These individuals presented with fever at the Malaria Laboratory and Infectious Diseases Hospital, Kuwait and were

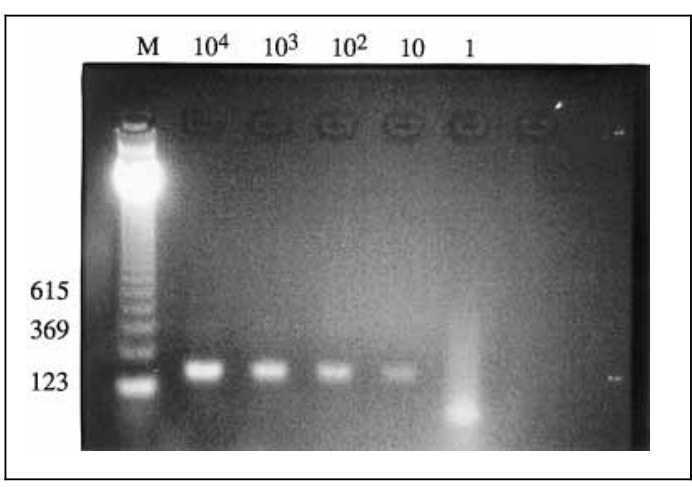

Fig. 1. Sensitivity of the PCR amplification of the P. falciparum ribosomal DNA gene. The figure shows detection sensitivity with known numbers of $P$. falciparum parasites diluted in fresh red blood cells (indicated at the top of each lane). Molecular size markers (lane M) flank the experimental lanes and are indicated in base pairs. Electrophoresis of the product was performed in $2.5 \%$ agarose gel.

diagnosed by the presence of malaria parasites in blood smears. Thick and thin blood smears were stained with $5 \%$ Giemsa stain for $10 \mathrm{~min}$ and examined under the microscope.

(ii) Suspected Malaria Cases. Blood samples were obtained from 50 individuals (S1-S50) who presented at the Malaria Laboratory with fever, and had a history of a recent visit to a malaria endemic area. No malaria parasites were detected in their peripheral blood by the Giemsa-stained thick and thin blood smears.

(iii) Controls. Twenty-five blood samples were collected from the individuals, mostly Europeans, residing in malaria-free countries. The microscopic examination of their peripheral blood films showed they were all negative for malaria parasite by microscopic examination of their peripheral blood films.

\section{P. falciparum-Specific PCR}

$P$. falciparum DNA was detected by PCR amplification of the small subunit ribosomal RNA gene using the MSP-2 primers. These primers were derived from the published sequence of the MSP-2 gene, which is highly conserved in all $P$. falciparum strains studied. The primers and cycling parameters were used as described by Snounou et al. [7] with slight modifications. Briefly, the parasite DNA was purified after incubation in $20-50 \mu \mathrm{l}$ of boiling buffer $(50 \mathrm{mM} \mathrm{KCl}$, 
Fig. 2. Representative $2.5 \%$ agarose gel showing amplification using PCR primers for human species-specific MSA-2 $3^{\prime}$ and MSA-2 $5^{\prime}$ to test for the presence of $P$. falciparum parasites in the samples. The expected size of the product is 137 base pairs (bp). The numbers at the left indicate size (bp) of molecular weight markers (lane $\mathrm{M}$ ), Lane 1, positive tb control (145 bp); lanes 3-9, clinical samples (designated as $\mathrm{C}$ ); lane 10, uninfected red blood cells as negative control (N); lane 11, sample C9.

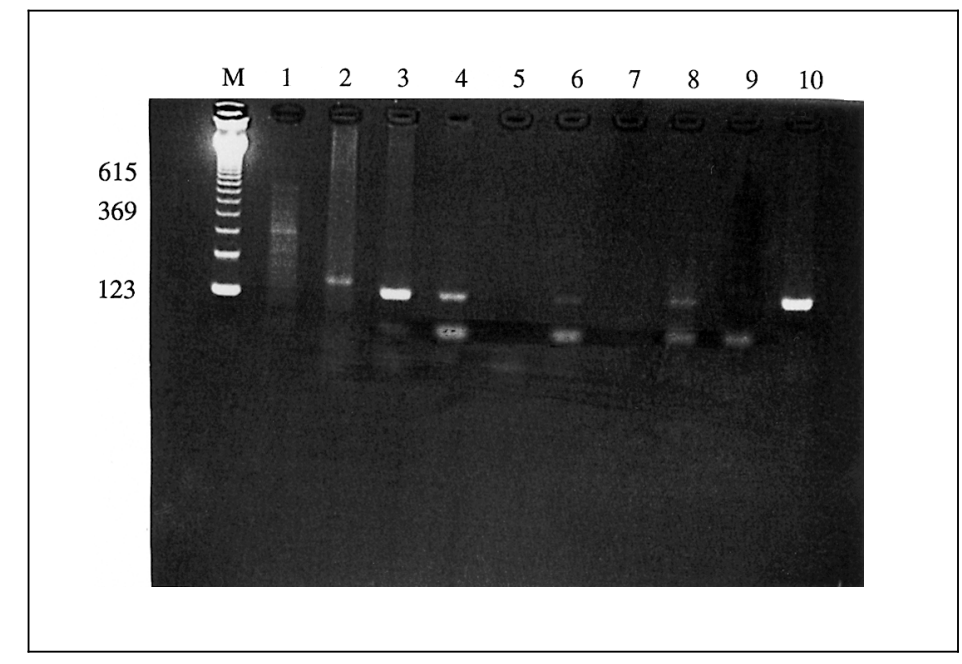

$10 \mathrm{~m} M$ Tris, $\mathrm{pH} 8.3,0.1 \mathrm{mg} / \mathrm{ml}$ gelatin) or extracted using phenol/chloroform as earlier described [7, 8]. All PCR reactions were carried out with $4 \mu \mathrm{l}$ of DNA in $20 \mu$ containing $2 \mathrm{mM} \mathrm{MgCl} 2 / 50 \mathrm{mM} \mathrm{KCl}, 10 \mathrm{~m} M$ Tris, $\mathrm{pH} 8.3(\mathrm{HCl}) / 0.1 \mathrm{mg} / \mathrm{ml}$ gelatin $/ 125 \mu M$ of each of the four deoxyribonucleotide triphosphates/125 $\mathrm{n} M$ of each oligonucleotide primer, and 0.4 units of AmpliTaq Polymerase (Perkin Elmer Cetus, USA). The PCR products were analysed on $2.5 \%$ agarose gels and visualized on an ultraviolet transilluminator after staining with ethidium bromide.

\section{Results}

\section{Blood Film Microscopy}

All the 50 cases included in the malaria group (C) were confirmed by microscopic examination of Giemsa-stained thick and thin blood films. The results are given in table 1. In only 5 samples, more than 100 parasites were found per 200 leucocytes. In the remaining 45 infected persons, parasitaemia was low (data not shown). All the 50 individuals in the suspected group (S) were negative for parasites on microscopy.

$P$. falciparum Infection in

Non-Endemic Kuwait
Sensitivity of the PCR Parasite Detection

To establish the sensitivity of the PCR assay, fixed numbers of $P$. falciparum parasites cultured in vitro were used in a limit dilution detection assay. Fresh uninfected blood was used as diluents. No amplification was observed when genomic DNA from uninfected blood was used as template (data not shown). The results were compared with that obtained from microscopic examination of Giemsa-stained thick blood films.

The sensitivity of the assay was in the order of 10-100 P. falciparum parasites per sample (fig. 1). The amount of human DNA (and parasite DNA if present) in each reaction was approximately equivalent to that in $5 \mu \mathrm{l}$ of blood in the sample. False negatives were not observed in the PCR assay, and all infections diagnosed by microscopy were confirmed by the amplification assay.

PCR assay was then performed to screen clinical samples. A representative sample of the PCR results obtaind is presented in figure 2. The PCR assay is not quantitative, and thus the product yield does not correlate with the level of parasitaemia. The amount of

Med Principles Pract 1998;7:277-282 279 
Table 1. Detection of $P$. falciparum parasites by PCR and microscopy in clinical specimens

\begin{tabular}{llll}
\hline Specimens & Method & $\begin{array}{l}\text { Total } \\
\text { positive }\end{array}$ & $\begin{array}{l}\text { Total } \\
\text { negative }\end{array}$ \\
\hline Infected cases & microscopy & 50 & 0 \\
& PCR & 50 & 0 \\
\hline Suspected cases & microscopy & 0 & 50 \\
& PCR & $6^{\mathrm{a}}$ & 44 \\
\hline Controls & microscopy & 0 & 25 \\
& PCR & 0 & 25 \\
\hline
\end{tabular}

a Three of the 6 cases were confirmed on re-examination of blood smears.

product amplified, however, was at times diminished when very low parasite numbers were present in the samples assayed (fig. 2, lanes 6 and 8). The results of the PCR assays were compared with that of microscopic examination of Giemsa-stained blood smears (table 1). For all the 50 smear-positive cases (C1-C50) a prominent specific 137-bp band was detected by PCR analysis. However, in 6 of the smear-negative cases from the suspected group a prominent specific 137-bp band was observed on PCR analysis.

\section{Detection of Infection in Suspected Malaria Cases}

All the 50 cases were negative for P. falciparum parasites on examination of Giemsastained thick and thin blood smears. However, 6 of these smear-negative cases were positive for P. falciparum infection on PCR analysis. The blood smear of these 6 PCRpositive but smear-negative cases was reexamined to confirm the diagnosis. Prolonged microscopic examination of thick and thin blood films confirmed the presence of $P$. falciparum parasites in 3 of the 6 cases.

\section{Discussion}

The measurement of parasite incidence is of fundamental significance in the design of malaria control measures. Monitoring of the distribution of all the Plasmodium species in the population is of particular importance before initiation of any control interventions, especially, when resistance to antimalarial drugs is exhibited by one or more of the species.

Microscopy has been traditionally used for the assessment of malaria parasites. Examination of blood films is ideally suited for rapid diagnosis and thus remains unsurpassed in the clinical setting, where parasite levels are relatively high. However, in hypo-endemic areas or where sub-patent infections are often encountered, the suitability of examination of blood films for malaria parasite detection is limited. There is no malaria transmission in Kuwait. The infections seen here are in individuals who had visited a malaria endemic area recently, or have residual or relapses of the malaria infection. Such patients may have sub-patent infections, in which the parasite numbers are often very low. The lengthy microscopic examination required to detect low parasitaemias not only restricts the number of samples that can be processed, but also makes it difficult to identify the parasite species. In thick blood films, parasites can be difficult to differentiate morphologically, in particular when only the ring stages are observed. This difficulty is exacerbated by the presence of morphologically atypical parasites in immune persons and those who have taken antimalarial drugs. In addition, the numerical dominance of one species by another in mixed infections often results in a failure to detect the rare species. In this study, a conservative detection limit of 10 parasites in $5 \mu \mathrm{l}(2$ parasites $/ \mu 1$ ) of blood is assumed, which corresponds to a parasitaemia of approximately 
$0.0004 \%$ (assuming $5 \times 10^{6}$ erythrocytes $/ \mu 1$ of blood). Such samples constitute very low parasitaemias and are most likely to be missed in the examination of the Giemsastained thick blood films, which have a sensitivity threshold of approximately 10-20 parasites $/ \mu 1$, even in experienced hands in good laboratory facilities.

The higher sensitivity and specificity of the PCR assay over microscopic diagnosis have been previously established [8-10]. In the present study, at least 6 cases (12\%) who were microscopically negative had PCR-detectable parasitaemia. Prolonged microscopic re-examination of thick and thin blood films of these cases confirmed the presence of $P$. falciparum parasites in 3 of the 6 cases.

Asymptomatic malaria infections are of course common in holo-endemic transmission zones in the wet tropics [11]. Although malaria transmission has not been reported in Kuwait, however, a large number of individuals working in Kuwait come from malaria holo- and hyperendemic areas. Many asymptomatic malaria infections are detected at the Malaria Screening Centre. The parasite density in most of these asymptomatic cases is very low and is often missed by the standard microscopic method. The individuals thus harbour the parasite for a variable period, and present clinically at a later stage when the parasitaemia is high, posing a greater health risk for the individual. Furthermore, treatment of such asymptomatic carriers is essential to eliminate the residual reservoir of infectious population, through whom mosquito-borne transmission can occur under favourable environmental conditions. In order to overcome these limitations, we introduced a highly sensitive PCR assay to screen very low levels of parasitaemia. The cost of the assay, although higher than that of microscopy, is justified by the quality of the results, effective diagnosis, treatment and management of sub-patent infections.

In conclusion, in this study we have standardized a PCR protocol for the detection of P. falciparm using MSA-2-specific primers. Our results show that PCR is a highly sensitive and specific assay which can detect very low levels ( 2 parasites $/ \mu 1$ of sample) of parasites and thus is of great value to obtain accurate detection of chronic, residual and subpatent infections in Kuwait.

\section{Acknowledgements}

We thank the physicians and laboratory technical staff at Infectious Diseases Hospital, Department of Microbiology, Faculty of Medicine and the Malaria Laboratory in Kuwait. Financial support for this study was provided by Kuwait University Research Administration Grant MI 089 and MI 098. 


\section{References}

1 Spielman A, Perrone JB, Teklehaimanot A, Balcha F: Malaria diagnosis by direct observation of centrifuged samples of blood. Am J Trop Med Hyg 1988;39:337-342.

2 Sethabutr O, Brown AE, Gingrich J, Webster HK, Pooyindee N, Taylor DN, Echeverria P: A comparative study of radiolabelled and enzymeconjugated synthetic DNA probes for the diagnosis of falciparum malaria. Am J Trop Med Hyg 1988;39: 227-231.

3 Laner DE, McLaughlin GL, Wirth DF, Barker RJ, Zolg JW, Chulay JD: Comparison of thick films, in vitro culture and DNA hybridization probes for detecting P. falciparum malaria. Am J Trop Med Hyg 1989; 40:3-6.

4 McLaughlin GL, Subramanian S, Lepers JP, RaharimalaKa L, Deleron P: Evaluation of a non-isotopic DNA assay kit for diagnosing $P$. falciparum malaria in Madagascar. Am J Trop Med Hyg 1993;48:211215.
5 Barker RH Jr, Banchongaksorn T, Courval JM et al: DNA probes as epidemiological tools for surveillance of P. falciparum malaria in Thailand. Int J Epidemiol 1994;23: 161-168.

6 Shute GT: The microscopic diagnosis of malaria; in Wemsdorfer WH, McGregor I (eds): Malaria, Principles and Practice of Malariology. London, Churchill Livingstone, 1988, pp 781-814.

7 Snounou G, Viriyakosol S, Jarra W, Thaithong S, Brown KN: Identification of the four human malaria parasite species in field samples by the polymerase chain reaction and detection of a high prevalence of mixed infections. Mol Biochem Parasitol 1993;58:283-292.

8 Snounu G, Pinheiro L, Goncalves A, Fonseca L, Dias F, Brown KN, Rosario Ve do: The importance of sensitive detection of malaria parasites in the human insect hosts in epidemiological studies, as shown by the analysis of field samples from Guinea Bissau. Trans Soc Trop Med Hyg 1993;87:649-653.
9 Barker RH Jr, Banchongaksorn T, Courval JM, Suwonkerd W, Rimwungtragoon $\mathrm{K}$, Wirth DF: A simple method to detect P. falciparum directly from blood sample using the polymerase chain reaction. Am J Trop Med Hyg 1992;56:416-426.

10 Roper C, Elhassan IM, Hviid L, Giha H, Richardson W, Babiker H, Satti GMH, Theander TG, Arnot DE: Detection of very low level $P$. falciparum infections using the nested polymerase chain reaction and a reassessment of the epidemiology of unstable malaria in Sudan. Am J Trop Med Hyg 1996;54:325331.

11 Greenwood B, Marsh K, Snow R Why do some African children develop severe malaria? Parasitol Today 1991;7:277-281. 